\title{
Case Study: COPD, CHF, Elder Abuse
}

\section{Harold Kovach}

Forensic Anthropologist, MS Criminal Justice, JD Owner \& EO, 409 Canary Lane, Statesboro, USA

*Corresponding author: Dr. Harold L Kovach, Ph.D, Forensic Anthropologist, MS.Criminal Justice, JD Owner \& EO, 409 Canary Lane, Statesboro, GA. 30461, USA, Tel: (912) 587-2016; E-mail: iccr.forensics@gmail.com

Rec date: July 15, 2015 Acc date: August 21, 2015 Pub date: August 27, 2015

Copyright: ( 2015 Kovach HL. This is an open-access article distributed under the terms of the Creative Commons Attribution License, which permits unrestricted use, distribution, and reproduction in any medium, provided the original author and source are credited.

\section{Case Study}

TJ is a 74-year-old Caucasian female, retired factory worker and waitress, widow, who lives in her own home with adult son and one other adult male "friend" (not a significant other). She has a complicated medical history including $\mathrm{O}_{2}$ dependent COPD, CHG, renal insufficiency, hypothyroidism, PVD, peptic ulcer disease. During the last year she has had multiple hospital admissions for COPD/CHF complications, and has been discharged to several different nursing homes and then to home on numerous occasions. She is very dependent on her son and friend for her physical cares. She was readmitted to Nursing Home on 12/29/95 after an abusive altercation with her son, who brought her to the Emergency Room and said he could no longer take care of her at home. Code status: FULL CODE.

\section{Current Problems}

\section{Skin integrity}

Multiple bruises on upper arms, torso and some are found on legs during admission. Small skin tears on arms at elbow and wrist. Skin integrity compromised by continuous use of steroids for respiratory problems.

\section{COPD}

Continuous problems with management of respiratory condition $\mathrm{R} / \mathrm{T}$ causing frequent hospitalizations and home environmental conditions, such as son smoking and also the presence of cat in home. Pt. also takes $\mathrm{O}_{2}$ off which leads to hypoxia leading to a decreased mental status and to hospitalization. Independence in activities of daily living was compromised by dyspnea on exertion. Respiratory balance maintained with $\mathrm{O}_{2}$ used at 3 litres, and inhalers.

\section{Psychosocial issues}

Pt. continues to be discharged to home environment that is not conducive to maximum disease management. Vulnerable adult status, such as son is under care of psychiatry clinic at XYZ Medical Center and has on several occasions pushed, grabbed pt. Home environment was poor for pt.'s existing physical condition. Pt. is almost totally dependent on others for her physical cares, but is most likely functionally able to do more than she does. Her son and friend do all the housework and cooking in addition to assisting her with her personal needs including dressing, bathing, taking pills. Home health care workers come in twice a week. Last altercation with son reported to Vulnerable Adult office upon ER admission. Caseworker was assigned.

\section{Past History}

\section{General state of health:}

For past several years health has been poor to fair. Currently, fair.

\section{Childhood illnesses:}

Pt. remembers having severe Scarlet Fever as child and thinks she had mumps, measles and chicken pox.

\section{Adult illnesses:}

Pt. is poor historian regarding time line; medical histories in chart are also poor.

- COPD, $\mathrm{O}_{2}$ dependent for 3 years. Respiratory failure with intubation $3 / 95$

- Congestive heart failure

- Chronic renal insufficiency

- Hypothyroidism

- Peripheral vascular disease

- Upper GI bleed/Epistaxis

- Squamous cell CA of larynx 1993; recurrence in 1995

- Peptic ulcer disease

- Inguinal hernia - "for years"

- Right bundle branch block with atrial fibrillation

- Anemia

- Lumbar/Thoracic compound Fx, secondary to steroid use

\section{Psychiatric illness:}

No history

\section{Accidents and injuries:}

None.

\section{Operations:}

Pt states several hernia operations - year unknown, not documented on chart. Cataract surgery, Left eye-year unknown.

\section{Hospitalizations:}

Numerous hospitalizations in last year documented for COPD exacerbations and CHF. 3/95, 4/95, 5/95, 6/95, etc. Last one 12/95. 


\section{Current Health Status}

\section{Allergies:}

Penicillin - breaks out in rash.

\section{Immunizations:}

2-step Mantoux, 1996. Refused to take flu shot this year. Pneumovax given, date unknown.

\section{Screening tests:}

Mini-Mental State Exam given 1/2/96 - Score of 26

\section{Environmental hazards:}

Cigarette-smoking son. Cat. House was condemned 8/95.

\section{Use of safety measures:}

Uses wheelchair at home. Uses commode.

\section{Exercise and leisure activities:}

Watches television. Exercise restricted R/T COPD.

\section{Sleep patterns:}

Goes to bed at 10:00 to 10:30, up at 6:00 a.m. sleeps well.

\section{Diet:}

Previous to admission had Meals on Wheels. No special diet.

\section{Current medications:}

- Cardiazem CD $180 \mathrm{mg}$ QD

- Ativan $0.5 \mathrm{mg}$ QD

- Prenatal Vitamins - one QD

- Prilosec 20 mg QD

- Levothyroxine $0.05 \mathrm{mg}$ QD

- Lasix 20 mg BID

- ASA.EC - one QD

- Slow Magnesium - BID

- Nitro transdermal patch $0.4 \mathrm{mg}$ - one in a.m., off at HS

- Atrovent MDI 2 puffs QID

- Proventil MDI 2 puffs QID

- Azmacort MDI 2 puffs QID

- Nitrostat - one Prn - chest pain, repeat x2 at 5 min. intervals

- Extra strength Tylenol - two, Q 4 hours Prn.

\section{Tobacco:}

Non-smoker for about 6 years, 45-90 packs a year before that.

\section{Alcohol use:}

Admits to drinking an "occasional beer" non-specific as to exact quantity.

\section{Family History}

\section{Children}

Has one son of indeterminate age. Chart states he is 25 years old, patient says he is in his forties but cannot recall what year he was born in or how old she was when she had him. Thinks she was in her late 20s. Healthy but mentally slow and has other mental health problems. Pt. states he had a "nervous breakdown" after his father died.

\section{Siblings}

Pt. is one of 13 children, 10 boys, and 3 girls. 3 are deceased from unknown causes. Pt. is only in occasional contact with one brother who is fairly healthy. Does not know about others. Parents are deceased - causes unknown.

\section{Psychosocial History}

\section{Home situation:}

See problem list. Care conference held on 1/9/96. Neither son nor friend attended. Pt. did not attend due to nausea. Pt. has had 2 home health visits per week while at home.

\section{Significant others:}

Just son, who is occasionally abusive.

\section{Daily life:}

Wheelchair bound, goes out in summer but not in winter, watches $\mathrm{TV}$. Is Lutheran, but religion does not play a big role in life and is not a source of support.

\section{Outlook on future:}

Feels everything will be all right if she can go back home. Wishes she would "get better" physically.

\section{Review of Symptoms}

- General: Overall feeling good.

- Skin: States she bruises easily and usually has bruises on arms and legs from bumping them. Denies rash, itching. Has dry skin in winter.

- Head: Denies headaches

- Eyes: States she cannot see out of right eye, left is better since cataract surgery.

- Ears: Denies hearing loss, itching and pain.

- Nose and sinus: Denies nasal congestion, sinus pain, nosebleeds.

- Mouth and throat: States no sores in mouth, has dentures but does not wear them. Denies difficulty swallowing. Occasional dry mouth.

- Neck: Denies swollen glands, pain.

- Breasts: States no lumps, but does not check breasts on a regular basis

- Respiratory: Denies shortness of breath at rest. Does become more short of breath with activity. (See current problem). Needs to sit up in bed with two pillows at night.

- Cardiac: Denies chest pain, palpitations, ankle swelling. 
- Gastrointestinal: Denies epigastric pain, heartburn, constipation and diarrhea.

- Urinary: No pain, frequency, burning. Denies leaking, incontinence. (Staff and son report infrequent episodes, usually nocturnal, of incontinence).

- Genital: Denies itching, pain, vaginal discharge.

- Peripheral vascular: Denies heat/cold sensitivity, numbness, tingling in extremities.

- Musculoskeletal: Denies pain in any joints, limited motion. Does get occasional muscle cramp in leg when she sits too long. Last about 30 seconds to one minute. Relieved by change of position and massaging area. States she often feels too "weak" to help with cares or any household chores. Refuses physical therapy.

- Neurologic: States that sometimes she can't remember exact dates (i.e., son's birthday).

- Hematologic: States bruises easily. Denies extraordinary fatigue.

- Endocrine: Denies heat/cold sensitivity, excessive fatigue, loss of hair, weight gain.

- Psychiatric: Denies mental health problems.

\section{Addendum}

Pt. does state that she would be hesitant to admit to any problems that would delay her discharge to home.

\section{Physical Assessment}

\section{General survey}

Pt. appears to be older than stated 74 years, slightly nervous answering questions (rubbing hands together, avoiding direct eye contact). BP 118/56, Weight 120.

\section{Integumentary System}

Skin fragile and slightly dry. Healing bruises visible on upper arms, several small $(<1 \mathrm{~cm})$ skin tears, healing, on left elbow, no drainage or redness. Skin warm to touch.

\section{Head and neck}

Skull and facial features symmetrical. Hair thin, gray. Thyroid not palpable, trachea midline. Lymph nodes not palpable.

\section{Nose, mouth, oropharynx and sinus}

No nasal drainage. No pain on palpation of frontal and maxillary sinuses. Oral mucosa pink and moist, no lesions under tongue. No teeth or dentures. Lips are dry, slightly gray tinged. TMJ intact, no crepitus or tenderness.

\section{Ears and auditory system}

No lumps or tenderness of external ear. Tympanic membrane intact, no cerumen. Able to hear whispered word without difficulty.

\section{Eyes and Visual System}

No nystagmus. No inflammation of eyelids. Sclera white. PERRL. Unable to examine eyes - no ophthalmoscope.

\section{Thorax and Lungs}

Symmetric chest expansion on respiration, no chest wall tenderness or masses. Air movement in all lung fields, rales in right lower lobe, less in left lower lobe. No consolidation noted on percussion. Strong, spontaneous cough reflex. No upper airway congestion. Respiratory rate 20, unlabored. No costovertebral tenderness. Able to speak full sentences without shortness of breath. Baseline Arterial blood gases; pH 7.40, CO2 43, O2 84.

\section{Cardiovascular system}

No murmurs. S1-S2 normal, no S3-S4. Apical pulse 80 and regular. No heaves or lifts. No JVD. No edema. Recent BP's stable.

\section{Peripheral vascular system}

All peripheral pulses present and equal. No carotid bruits. No varicose veins. No calf pain.

\section{Breasts}

Breasts symmetrical, sagging. No dimpling, nipple discharge. No nodules noted in breast tissue or axilla. No rash.

\section{Gastrointestinal system, abdomen}

Abdomen is asymmetrical due to large, protruding umbilical hernia. Old scar tissue from previous hernia surgery present. Bowel sounds present in all four quadrants. Liver palpation deferred due to hernia. No abdominal tenderness or other superficial masses palpated. No external hemorrhoids noted. Has one extra piece of tissue (tag) by rectum. Rectal exam deferred per pt. request.

\section{Genitalia}

No vaginal discharge. Labia atrophied. No rashes. Pelvic exam deferred.

\section{Musculoskeletal}

Pt. able to move all extremities. Able to transfer from wheelchair to bed and back by self. Able to ambulate short distances with $\mathrm{O}_{2}$ on, gait steady. Able to lift arms overhead, lift legs in sitting and lying position.

\section{Neurological system}

Cranial nerves II-XII intact. Alert, oriented x 3, positive affect. Equal strength hand grasp. Sensory function positive for light touch. DTRs deferred due to no instrument. Sits slightly slumped in wheelchair. Speech clear.

\section{Psychological}

Pt. tends to avoid answering questions dealing with abusive interactions with son or any questions that pertain to problems with her living situation. Tries to convince interviewer that everything is fine, that there are no problems. In her desire to go home she creates a very positive picture that is not in synch with past events. In Nursing Home pt. is a loner who prefers to stay in her room and does not participate in any activities. Concern is that pt. will not tell of any physical problems that might keep her in the nursing home longer (Tables 1-6). 


\begin{tabular}{|l|l|}
\hline RELEVANT Data from Present Problem: & Clinical Significance: \\
\hline & \\
\hline RELEVANT Data from Social History: & \\
\hline & Clinical Significance: \\
\hline & \\
\hline
\end{tabular}

Table 1: What data from the histories is important \& RELEVANT; therefore it has clinical significance to the nurse?

\begin{tabular}{|l|l|}
\hline PMH: & Home Meds: \\
\hline & \\
& \\
& \\
\hline
\end{tabular}

Table 2: What is the RELATIONSHIP of your patient's past medical history (PMH) and current meds? (Which medications treat which conditions? Draw lines to connect).

\begin{tabular}{|l|l|}
\hline RELEVANT Assessment Data: & Clinical Significance: \\
\hline & \\
& \\
\hline
\end{tabular}

Table 3: What assessment data is RELEVANT that must be recognized as clinically significant?
RELEVANT Assessment Data:
Clinical Significance:

Table 4: What assessment data is RELEVANT that must be recognized as clinically significant?

\begin{tabular}{|l|l|l|}
\hline Nursing Interventions: & Rationale: & \\
\hline & & \\
& \\
\hline
\end{tabular}


Table 5: Clinical reasoning begin.

1. What is the primary problem that your patient is most likely presenting with?

2. What is the underlying cause/pathophysiology of this concern?

3. What nursing priority(s) captures the "essence" of your patient's current status and will guide your plan of care? (If more than one-list in order of PRIORITY)

4. What interventions will you initiate based on this priority?

5. What body system(s) will you most thoroughly assess based on the primary problem or nursing care priority?

6. What is the worst possible/most likely complication to anticipate based on the primary problem?
7. What nursing assessments will identify this complication EARLY if it develops?

8. What nursing interventions will you initiate if this complication develops?

9. What educational/discharge priorities will you identify for this patient?

10. Identify 2 Nursing Diagnoses and Prepare a Nursing Care Plan. (Use the NCP form from Folio).

\begin{tabular}{|l|l|l|l|}
\hline Medication/Dose: & Mechanism of Action: & $\begin{array}{l}\text { Volume/time frame to Safely } \\
\text { Administer: }\end{array}$ & Nursing Assessment/Considerations: \\
\hline & & & \\
\hline
\end{tabular}

Table 6: Medication dosage calculation. 